\title{
Modeling of the Regeneration Processes in Diesel Particulate Filters
}

\author{
Leonid Tartakovsky ${ }^{*}$, Boris Aronov, Yoram Zvirin \\ Faculty of Mechanical Engineering, Technion, Israel Institute of Technology, Haifa, 32000, Israel
}

\begin{abstract}
New simulation algorithm of soot oxidation in diesel particulate filter (DPF) is proposed. Two-dimensional finite differences scheme is used for calculation of the heat transfer in DPF (macro-scale). One dimensional model for treatment of the soot oxidation process in a separate filter channel (micro-scale) is based on a new expression for the oxidation reaction rate that is a modification of the known Bissett's equation. This expression allows consideration of the non-linear dependence of oxidation reaction rate on a reagent concentration. For cases of catalytic coating a modification of the known two-layer model is suggested. A fraction of soot that has been oxidized with the help of the catalyst is not invariable in the first layer, but it exponentially depends on the distance from a channel wall of the particle trap. Soot oxidation by $\mathrm{O}_{2}$ and/or $\mathrm{NO}_{2}$ in diesel particulate filters is investigated for various cases of non-catalytic and catalytic oxidation. The filter clogging propagation from its periphery to the center at critical temperature is described theoretically at first. A comparison between various types of DPF regeneration methods is performed by using the proposed simple simulation algorithm and appropriate computer code.
\end{abstract}

Keywords Diesel particulate filter, Filter regeneration, Soot oxidation

\section{Introduction}

Diesel particulate filters are the most effective option to control the particulate matter (PM) emissions[1-4]. Today there are several types of DPF available on the market and differing mainly by the method of trapped soot removal usually called filter regeneration. It is convenient to classify regeneration methods as active (applying external or engine measures of gas temperature control at DPF inlet) or passive (usually employing catalytic means)[2],[5],[6]. Com binations of measures are also common and catalytic means can be applied in active regeneration systems. Between active regeneration methods utilizing engine measures of gas temperature control at DPF inlet the following means can be noted[2]: exhaust gas recirculation (EGR), injection timing retard, fuel post-injection, decrease of boost pressure, intercooler bypass. The external means of active regeneration include: fuel burners with full or partial flow, filter electric heaters, microwave heaters, injection of combustibles, catalytic or reactive species in the exhaust[7], electrochemical filter reactor[8], etc. Increase of the exhaust gas temperature to about $600^{\circ} \mathrm{C}$ (temperature of non-catalytic soot oxidation) by fuel burners, electric heating, etc. incur additional energy costs, require

* Corresponding author:

tartak@technion.ac.il (Leonid Tartakovsky)

Published online at http://journal.sapub.org/ep

Copyright (C) 2012 Scientific \& Academic Publishing. All Rights Reserved complex means of control and can createsignificant thermal stresses on filter components. Passive regeneration methods include: catalytic filter coatings[9], fuel-borne catalysts (FBC)[10], reactive species generation (e.g. $\mathrm{NO}_{2}$ )[11]. The development of catalyzed DPF (CDPF) aims at attaining[2]: soot oxidation activity under moderate exhaust temperatures by exploiting direct (through oxygen transfer) as well as indirect (through $\mathrm{NO}_{2}$ generation) soot oxidation; reduced soot ignition temperatures compared tonon-catalyzed filters to allow energy savings during fixed regenerations; tolerance to ash accumulation. Despite a significant number of works in this field, there is still no consensus about the ability of CDPF to catalyze the direct oxidation of PM at lower temperatures and under conditions relevant to real-world applications[9]. The latest findings in this field show that the mechanism of the direct catalytic combustion of soot is attributed to a two-step process: initial direct combustion initiated by oxygen transfer from catalyst to soot, which is followed by an exothermal propagation to soot particles spatially discrete from direct contact. This mechanism is not dependent on $\mathrm{NO}_{2}$ content[9]. Other popular DPF regeneration methods use $\mathrm{NO}_{2}$ - oxidation with $\mathrm{O}_{2}$ presence without or with catalytic coating on the filter (Continuously Regenerating Trap (CRT) or Catalyzed Continuously Regenerating Trap (CCRT), respectively)[3],[11]. CRT and CCRT systems usually use a diesel oxidation catalyst (DOC) located upstream a DPF to promote $\mathrm{NO}_{2}$ generation from the engine-out $\mathrm{NO}$ emissions. The mentioned above methods of DPF regeneration differ 
by their cost, reliability, minimal required exhaust gas temperature and $\mathrm{NO}_{\mathrm{x}}$ concentrations, etc.

Processes of DPF regeneration have been studied and described in numerous publications. The $\mathrm{NO}_{2}$-carbon oxidation reaction follows the Langmuir-Hinshelwood mechanism and characterized by activation energy values far below those for $\mathrm{C}+\mathrm{O}_{2}$ reactions and by non-linear dependence of the reaction rate, $R$, on $\mathrm{NO}_{2}$-concentration. Messerer et al.[12] has found experimentally that at $\mathrm{NO}_{2}$ concentrations above $200 \mathrm{ppm}$ the reaction rate increase with $\mathrm{NO}_{2}$ fraction growth saturates. However, many modeling approaches apply the classic Bissett equation, and soot oxidation is assumed to be the first order reaction in $\mathrm{NO}_{2}[13],[14]$.

For non-catalytic $\mathrm{O}_{2}$-carbon oxidation the activation energy $E_{\mathrm{O}_{2}}$ value of $180 \mathrm{~kJ} / \mathrm{molwas}$ suggested byKonstandopolous and Kostoglou[15]. Jacquot et al.[16] obtained $E^{(l)}{ }_{\mathrm{NO} 2}=45.5 \mathrm{~kJ} / \mathrm{mol}$ for the reaction $\mathrm{C}+2 \mathrm{NO}_{2} \rightarrow$ $\mathrm{CO}_{2}+2 \mathrm{NO}$ and $E^{(2)} \mathrm{NO}_{2}=59.4 \mathrm{~kJ} / \mathrm{mol}$ for that of $\mathrm{C}+\mathrm{NO}_{2}$ $\rightarrow C O+N O$. These values are adopted here. Some promising catalysts have been reported in[17],[18] which can catalyze the $\mathrm{C}+\mathrm{O}_{2}$ reaction. Fino and Specchia[17] obtained activation energy of $123 \mathrm{~kJ} / \mathrm{mol}$ for catalytic $\mathrm{O}_{2}$-carbon oxidation by the development of a new soot combustion catalyst, $\mathrm{PrCrO}_{3}$ perovskite on $\mathrm{CeO}_{2}$. Palmisano et al.[18] produced nano-particles of ceria by combustion synthesis with catalytic activation energy of $111 \mathrm{~kJ} / \mathrm{mol}$ and temperature peak of carbon oxidation of $405 \mathrm{C}$. Wall-flow filters were studied by Konstandopoulos\&Kostoglou[19] under conditions of $\mathrm{O}_{2}$ oxidation and by Konstandopoulos et al.[20],[21] with $\mathrm{NO}_{2}$ - and $\mathrm{O}_{2}$-carbon oxidation. $\mathrm{FBC}$ that are supplied with the fuel were discussed in[21]. They were investigated, as well as wash-coated filters, by Hinot et al.[22]. It was found that Pt-doped soot and simultaneously filtered aerosols were both equally effective in reducing the oxidation temperature by up to $140-250^{\circ} \mathrm{C}$. Conversely, the deposition of a thin soot layer of 5-10 micron thickness onto Pt produced only a slight temperature decrease of about $13-42^{\circ} \mathrm{C}$. It should be noted that the $\mathrm{FBC}$ approach is inconvenient because of the inherent requirement of providing a continuous additive supply to the fuel, which also leads to its continuous consumption and to accumulation of metal oxide (ash) inside the DPF[23]. However, latest developments of FBC, e.g. Fe-based FBC described by Rocher et al.[10], aimed at mitigation of this drawback mainly by reduction of the required FBC dosing rates.

It is important to have an integrated simulation tool that will enable comparison between various types ofregeneration methods, in order to select the optimal configuration for the given type of vehicle and its driving characteristics. Development of such a tool is the goal of the work presented in this paper. It is the same objective as in[24]. Nevertheless, authors believe that their proposed model is useful due to its simplicity, more accurate heat transfer prediction (because of using two-dimensional scheme) and obtained new results.
New expression for the oxidation reaction rate with non-linear dependence of it on a reagent concentration is proposed, which makes possible simulation of both $\mathrm{O}_{2}$ - and $\mathrm{NO}_{2}$-carbon oxidation reactions. For cases of catalytic coating a modification of the known two-layer model is suggested. A fraction of soot that has been oxidized with the help of a catalyst is not invariable in the first layer, but it exponentially depends on the distance from a channel wall of the particle trap.

In macro-scale, for calculation of a temperature field in the whole filter the two dimensional finite differences scheme is used. A comparative study of various DPFregeneration methods is performed using the developed model, corresponding computer code and based on the proposed new approach.

\section{Simulation Model}

\subsection{Main Assumptions}

The simulation model described here is for particulate filters with a structure of alternate plugged channels (blocked at their ends - wall-flow filters, proposed by Howitt\&Montierth[25]). The continuum approach for this structure, which has been first introduced by Aris[26], is adopted for calculation of the filter temperature field, $T(z, x)$. Following Zhang et al.[27], a single temperature field (two-dimensional in the model) is used for the multiphase continuum consisting of three phases: exhaust gas, porous walls and particulate matter, excluding cases when part of the filter is blocked by the accumulated deposits. In the latter case there are only two phases remain: the structure walls and the particulate matter. Accumulation of soot in the wall is not considered. The findings of Mulone et al.[28] show that "theoretical wall capacity of particle collecting is never fully exploited allowing for a low impact of the wall onto backpressure". The assumption of the pressure derivative steadiness along axis $z$ is adopted. The latter allowed considering the momentum balance integrally.

Other assumptions, for the whole filter as a continuum, are as follows: the deposits distribution over the filter length (z-axis) is uniform; the porous channel walls and soot deposits on them are taken into account by effective values of densities, radial thermal conductivities and volumetric specific powers; the continuum velocity is directed along the filter axis.This assumption is based on the fact that the exhaust gases from the inlet channels of the trap arrive to the outlet channels from all directions. Thus, there is no radial flow in the macro scale.

Obtained $T(z, x)$ is used for the soot deposit calculations in the channels along the radial coordinate $x$ after $T(z, x)$ averaging over axis coordinate $z$. These calculations for each radial coordinate $x$ are performed by applying the one-dimensional one- or two-layer model. One-layer model is used for investigation of the non-catalytic and FBC catalyzed carbon oxidation by nitrogen dioxide or/and oxygen. The investigation of filters that are coated with a 
catalyst is performed by means of the two-layer mathematical model, similar to that developed by Konstandopoulos and Kostoglou[19] and differs from the latter by exponential dependence of the catalytic fraction of soot oxidation in the first layer on the distance from a channel wall of the particle trap coated by a catalyst. This model allows considering catalytic and non-catalytic oxidation by $\mathrm{O}_{2}$ and by $\mathrm{NO}_{2}$ separately or as a combination.

The following assumptions similar to those of Mohammed et al.[29], for the single channel, are made: the temperatures of the gas, the species concentration, the gas velocities and properties are taken as average across the channelcross-section; there are no variations of the species concentration in the exhaust gas along the length of the inlet channel; the gas is considered as ideal.

Based on these assumptions, the equations of: reaction rate; soot \& ash deposit evolution; formation of $\mathrm{NO}_{2}$ by catalyzing the oxidation of $\mathrm{NO}$ (if appropriate); total pressure drop; mass, momentum and energy conservation were solved in this model. All the heat transfer mechanisms: convection, conduction and radiation were taken into account by calculation of the effective value of thermal conductivity in the radial direction. The heat transfer in the axial direction is caused by mass transfer, with the exception of clogged parts of the filter (if existing). Only thermal conduction takes place in the latter regions.

\subsection{Basic Equations}

The new general equation for the oxidation reaction rate, $R_{x}\left[\mathrm{~kg} /\left(\mathrm{m}^{2} \mathrm{~s}\right)\right]$ of reagent $X$, is proposed

$$
R_{X}=\rho \bullet U \bullet w_{X}^{\varsigma} \bullet\left\{1-\exp \left[-S \bullet k \bullet\left(I-\phi_{C O}\right) \bullet d / U\right]\right\}
$$

Here: $\rho-$ gas density $\left[\mathrm{kg} / \mathrm{m}^{3}\right] ; U-$ gas velocity in the trap channels $[\mathrm{m} / \mathrm{s}] ; w_{x}$ - mass fraction of reagent $X ; S-$ soot specific surface, equal to $5.5^{\times} 10^{6}\left[\mathrm{~m}^{-1}\right]$ according to[30]; $d-$ soot layer thickness $[\mathrm{m}] ; k-$ kinetic coefficient $[\mathrm{m} / \mathrm{s}]$; Iis integer ( 1 or 2$), \phi_{C O}$ is $\mathrm{CO}$ selectivity for $\mathrm{O}_{2}$-or $\mathrm{NO}_{2}$-carbon oxidation and $\zeta$ is a fractional exponent. This expression is a modification of the well-known Bissett equation[30] and differs from it by the presence of a fractional exponent $\varsigma$. The latter allows better prediction of the reaction rate forcarbon-by- $\mathrm{NO}_{2}$ oxidation, which fits well with the experimental findings of Messerer et al.[12].

The basic equation for the oxidation reaction rate by $\mathrm{O}_{2}$, $R_{\mathrm{O}_{2}}\left[\mathrm{~kg} /\left(\mathrm{m}^{2} \mathrm{~s}\right)\right]$, obtained by Bissett[30], that corresponds to $\varsigma=1, I=1, X=O_{2}, \varphi_{C O}=f_{C O} / 2$ in equation (1), is implemented in this work for the cases of catalytic and non-catalytic $\mathrm{O}_{2}$-carbon oxidation:

$$
\mathrm{C}+\left(1-f_{\mathrm{CO}} / 2\right) \mathrm{O}_{2} \Rightarrow f_{\mathrm{CO}} \mathrm{CO}+\left(1-f_{\mathrm{CO}}\right) \mathrm{CO}_{2}(2)
$$

$f_{C O}$ value is determined as [15]:

$$
f_{C O}=1 /\left[1+\alpha \cdot y^{\gamma} \cdot \exp \left(T_{e f f} / T\right)\right]
$$

Where: $y$ - molar fraction of the oxidant; $\alpha, \gamma$ - coefficients; $T$-temperature $[\mathrm{K}]$ and $T_{\text {eff }}$-empirical value. The selectivity, $f_{C O}$, is different for thermal and catalytic oxidation processes.
For the former, it is denoted by $f^{\text {th }}{ }_{C O}=f_{C O}$ and for the latter by $f^{c a t}{ }_{C O}=f_{C O}^{\prime}$. For catalytic oxidation the other parameters are similarly denoted, e.g. $\alpha^{\prime}$. The values of these parameters are taken from Konstandopoulos\&Kostoglou[15] and Huynh et al.[31]: $T_{\text {eff }}=E_{f} / R=3000 \mathrm{~K}, T_{\text {eff }}^{\prime}=E_{f}^{\prime} / R=2575 \mathrm{~K} ; \alpha=$ $0.02, \alpha^{\prime}=3.57 ; \gamma=\gamma^{\prime}=0.21$, where $R$ is the universal gas constant. The kinetic coefficient $k$ in eq. (1) (for $\mathrm{O}_{2}$ oxidation) is given by:

$$
k=k_{O_{2}} \cdot T \cdot \exp \left(-E_{a c t} / R T\right)
$$

where $k_{O_{2}}=25.1 \mathrm{~m} / \mathrm{s}-\mathrm{K}$ and $k_{O_{2}}^{\prime}=1.23 /(1-\beta) \mathrm{m} / \mathrm{s}-\mathrm{K} ; \beta$ - index for the completeness of the catalytic soot oxidation. The values of the activation energies studied in this work are: $E_{O_{2}}^{\text {th }}=150-180 \mathrm{~kJ} / \mathrm{mol}$ and $E_{O_{2}}^{c a t}=102-120 \mathrm{~kJ} / \mathrm{mol}$. In the case of catalytic oxidation by oxygen, the two mechanisms are competitive and according to Konstandopoulos\&Kostoglou[15], the reaction rates for thermal and catalytic carbon oxidation are:

$$
\begin{gathered}
R_{O_{2}}^{t h}= \\
\rho \cdot U \cdot w_{O_{2}} \cdot\left[1-\exp \left(-S \cdot k^{*} \cdot d / U\right)\right] \cdot(1-\beta) \cdot k^{t h} \cdot\left(1-f_{C O} / 2\right) / k^{*} \\
R_{O_{2}}^{c a t}=\rho \cdot U \cdot w_{O_{2}} \cdot\left[1-\exp \left(-S \cdot k^{*} \cdot d / U\right)\right] \cdot \beta \cdot k^{c a t} \cdot\left(1-f^{\prime}{ }_{C O} / 2\right) / k^{*} \\
k^{*}=(1-\beta) \cdot k^{t h} \cdot\left(1-f_{C O} / 2\right)+\beta \cdot k^{c a t} \cdot\left(1-f^{\prime}{ }_{C O} / 2\right)
\end{gathered}
$$

The soot deposit evolution is determined by the following equation:

$$
\frac{d(\rho \cdot d)}{d t}=-\left[\frac{M_{C}}{M_{O_{2}}\left(1-f_{C O} / 2\right)} R_{O_{2}}^{\text {th }}+\frac{M_{C}}{M_{O_{2}}\left(1-f^{\prime}{ }_{C O} / 2\right)} R_{O_{2}}^{c a t}\right](8
$$

Here $M_{c}$ is the molecular weight of the soot deposit and $M_{O_{2}}$ is that of oxygen.

The $\mathrm{NO}_{2}$-carbon oxidation reaction follows a Langmuir-Hinshelwood mechanism which assumes that the reaction order $\zeta$ is non-equal $1-$ see eq. (1). In the case of carbon-by- $\mathrm{NO}_{2}$ oxidation, the reaction rate, $R$, depends only on the $\mathrm{NO}_{2}$ concentration $y_{\mathrm{NO}}$ and the equation for it reduces to- $d y_{\mathrm{NO}_{2}} / d t=$ const $\cdot y^{\zeta} \mathrm{NO}_{2}$. For the first-order mass evolution reaction $\zeta=1$ and an integration of the latter equation results in the form of eq. (1) for carbon-by- $\mathrm{NO}_{2}$ oxidation in DPF for the reaction rate on the channel wall of the trap, as was obtained in[30]. However, the simulation results of the reaction rate with $\zeta=1$ for carbon-by- $\mathrm{NO}_{2}$ oxidation were found to be lower by two orders of magnitude than the experimental data of Messerer et al.[12]. This indicates that the reaction is not really of the first order. Therefore, the appropriate reaction is called in this paper as the "pseudo first order reaction", and the value of $\zeta$ adopted in this work is equal to 0.5 since it is best suited to the experimental results obtained in[12]. Therefore, the reaction rate equation for carbon-by- $\mathrm{NO}_{2}$ oxidation can be written as:

$$
\begin{aligned}
& R_{\mathrm{NO}_{2}}= \\
& \rho \cdot U \cdot \sqrt{y_{\mathrm{NO}_{2}}} \cdot\left\{1-\exp \left[-S^{*} k_{\mathrm{NO}_{2}}\left(2-g_{\mathrm{CO}}\right) * d / U\right]\right\}
\end{aligned}
$$

Here $y_{\mathrm{NO}_{2}}$ is the $\mathrm{NO}_{2}$ mole fraction. In fact, since the reaction $2 \mathrm{NO}_{2}+\mathrm{C} \Rightarrow 2 \mathrm{NO}+\mathrm{CO}_{2}$ is dominant[20], it is possible to set the selectivity $g_{C O}$ as equal to 0 . 
The kinetic coefficient $k_{\mathrm{NO}_{2}}$ (used in eq. 9) and obtained by Jacquot et al.[16] is adopted here:

$$
k_{\mathrm{NO}_{2}}=\left(k_{\mathrm{CO}_{2}} \cdot p_{\mathrm{NO}_{2}}^{\eta}+k_{\mathrm{CO}} \cdot p_{\mathrm{NO}_{2}}^{\lambda}\right) \cdot L,
$$

where: $L$ - channel length $[\mathrm{m}] ; p_{\mathrm{NO}_{2}}$ is $\mathrm{NO}_{2}$ partial pressure $[\mathrm{Pa}] ; \eta=1.13, \lambda=1.05$ - parameters; and the kinetic coefficients $k_{\mathrm{CO}_{2}} \& k_{\mathrm{CO}}$ are given by:

$$
\begin{aligned}
& k_{\mathrm{CO}_{2}}=1.02 \cdot 10^{-3} \cdot \exp (-45,500 / R T) \\
& k_{\mathrm{CO}}=5.56 \cdot 10^{-3} \cdot \exp (-59,430 / R T)
\end{aligned}
$$

In recent works of Jeguirim et al.[32],[33] the kinetic coefficients are obtained for soot oxidation reactions by $\mathrm{O}_{2}$ and $\mathrm{NO}_{2}$ with and without coating by Ruthenium and Platinum on a channel wall of the trap. In the latter case oxidation starts from the conversion of $\mathrm{NO}$ into $\mathrm{NO}_{2}$. The following expression for the $\mathrm{NO}_{2}$ molar concentration $y_{\mathrm{NO}_{2}}$ as a function of the $N O$ molar concentration $y_{N O}$ and the temperature, for the case of a catalytic oxidation with Pt, has been derived here from the work of Cooper and Thoss[34]:

$$
y_{\mathrm{NO}_{2}}=0.00125 \cdot y_{\mathrm{NO}} \cdot T \cdot \exp \left[-\left(\frac{T-590}{135.33}\right)^{2}\right]
$$

The equation for soot deposition evolution in this case is obtained by adding on the right-hand-side (RHS) of eq. (8) the corresponding term:

$$
\begin{aligned}
& \frac{d(\rho \cdot d)}{d t}=-\left[\frac{M_{C}}{M_{\mathrm{O}_{2}}{ }^{\left(1-f_{C O} / 2\right)}} R_{\mathrm{O} 2}^{t h}\right. \\
& \left.+\frac{{ }_{C}}{{ }_{\mathrm{O}_{2}}{ }^{\left(1-f^{\prime} \mathrm{CO}^{\prime 2)}\right.}} R_{\mathrm{O}_{2}}^{c a t}+\frac{M_{C}}{M_{\mathrm{NO}_{2}}{ }^{\left(2-g_{C O}\right)}} \cdot R_{\mathrm{NO}_{2}}\right]
\end{aligned}
$$

In the case of filters with catalytic coatings, the two-layer model is adopted as mentioned above. The thickness of the thin first layer, adjacent to the filter wall, can be taken as $d_{l}=$ $10 \mu \mathrm{m}$. The catalyst effect on the carbon oxidation occurs in the first layer only and is determined by a criterion for the fraction of soot that has been oxidized with the help of the catalyst: the index $\beta$. On the catalytic layer surface $\beta$ is equal to 0.5 , as was suggested by Darcy et al.[35], and inside the second layer $\beta=0$. In the first layer the following dependence of $\beta$ on a distance from the channel wall $x$ is proposed:

$$
\beta(x)=\beta(0) \exp \left(-x / d_{1}\right)
$$

where $\beta(0)$ is the $\beta$ value on the catalytic layer surface. In this work $\beta(0)=0.5$.

If the soot deposit thickness is lower than or equal to $d_{l}$, all the equations for the one-layer model hold. For the one-layer model, non-catalytic or fuel borne catalyst oxidation, $\beta$ is equal to 0 or to a constant close to 1 (Konstandopoulos\&Kostoglou[15]), respectively.

\subsection{Modifications to the Basic Equations in the Two-Layer Model}

The carbon oxidation process in the second layer is not affected by the presence of a catalyst in the case of catalytic coatings on the filter wall. Hence, equations $(1-4,8)$ for $\mathrm{O}_{2}$ oxidation and $(9-12)$ for $\mathrm{NO}_{2}$ oxidation are of the same form in this case. It is evident that in eqs. (1) and (9) for the corresponding reaction rates the soot layer thickness $d$ is replaced by $d_{2}=d-d_{l}$. In eq. (8) for the soot deposit evolution, the term including $R^{\text {cat }} \mathrm{O}_{2}$ is set equal to 0 and the term

$$
-\frac{M_{\mathrm{C}}}{M_{\mathrm{NO}_{2}}\left(2-g_{\mathrm{CO}}\right)} \cdot R_{\mathrm{NO}_{2}}
$$

is added on the RHS (as for eq. 13) in the case of $\mathrm{NO}_{2}$ oxidation. In this case the soot evolution equation is:

$$
\begin{aligned}
& \frac{d\left(\rho \cdot d_{2}\right)}{d t}=-\left[\frac{M_{C}}{M_{\mathrm{O}_{2}}{ }^{\left(1-f_{\mathrm{CO}} / 2\right)}} \cdot R_{\mathrm{O}_{2}}^{\text {th }}\left(d_{2}\right)\right. \\
& \left.+\frac{M_{\mathrm{C}}}{M_{\mathrm{NO}_{2}}{ }^{\left(2-g_{\mathrm{CO}}\right)}} R_{\mathrm{NO}_{2}}\left(d_{2}\right)\right]
\end{aligned}
$$

In the reaction rate equations $(5,6,9)$ for the first layer, the consumption of the reagents $\mathrm{O}_{2}$ or $\mathrm{NO}_{2}$ in the second layer must be taken into account. Thus, in these equations the corresponding reagent concentrations must be replaced by the following[29] for the $\mathrm{O}_{2}$ oxidation process:

$$
w_{O_{2}, 1}=w_{O_{2}} \cdot \exp \left[-\frac{S \cdot k\left(1-f_{C O} / 2\right) \cdot d_{2}}{U}\right]
$$

and for the $\mathrm{NO}_{2}$ oxidation:

$$
y_{\mathrm{NO}_{2}, 1}=y_{\mathrm{NO}_{2}} \cdot \exp \left[-\frac{S \cdot k_{\mathrm{NO}_{2}}\left(2-g_{\mathrm{CO}}\right) \cdot d_{2}}{U}\right]
$$

The values of $w_{O^{2}, I}$ and $y_{\mathrm{NO}_{2}, 1}$ calculated by eqs. $(16,17)$ replace those of $w_{\mathrm{O}_{2}}$ and $y_{\mathrm{NO}_{2}}$ in eqs. $(5,6,9)$.

\subsection{Other Equations}

Pressure drop along the channel of the diesel particulate trap is expressed as in[36]:

$$
\Delta p=\frac{\mu Q}{2 V}(b+D)^{2}\left[\frac{D}{K b}+\frac{1}{2 K_{\text {soot }}} \ln \left(\frac{b}{b-2 d}\right)+\frac{4 F L^{2}}{3}\left(\frac{1}{(b-2 d)^{4}}+\frac{1}{b^{4}}\right)\right]
$$

where: $\mu$ - dynamic viscosity $[\mathrm{kg} / \mathrm{m}$-s $] ; Q$-exhaust gas volumetric flow $\operatorname{rate}\left[\mathrm{m}^{3} / \mathrm{s}\right] ; \quad V-$ filter volume $\left[\mathrm{m}^{3}\right] ; b-$ honeycomb filter cell width[m]; $K, K_{\text {soot }}$ - filter wall and soot permeability $\left[\mathrm{m}^{2}\right] ; D, d-$ channel wall and soot layer thickness, respectively[m]; $F=28.5$ - constant.

The values of permeability, $K$ and $K_{\text {soot }}$ are taken from Versaevel et al.[37] and Huynh et al.[31], respectively: $K=$ $3.3 \cdot 10^{-13}, K_{\text {soot }}=2 \cdot 10^{-14}\left[\mathrm{~m}^{2}\right]$. The non-homogeneity of the soot layer thickness in the radial direction was taken into account in the proposed model: the temperature field, $T(z, x)$, depends on the radial and longitudinal directions and the soot oxidation is a function of the $T$. The pressure drop along the whole trap was calculated by application of an electrical network analogy, in which $\Delta p$ was treated as a resistance. The values of the above-listed parameters are taken from[27] $(Q=677[\mathrm{scm} / \mathrm{h}] ; b=0.0015[\mathrm{~m}] ; D=0.31[\mathrm{~mm}])$ or from specification of the considered vehicle. The radial velocity component $U_{r}(x)[\mathrm{m} / \mathrm{s}]$ in micro-scale is used for the soot deposit evolution calculations. It is calculated from the following expression: 


$$
U_{r}(x)=0.25 * U_{Z}(x) * a(x) / L
$$

where $a(x)[\mathrm{m}]$ is the size of the filter channel part that is free of deposits, and the longitudinal velocity $U_{z}(x)[\mathrm{m} / \mathrm{s}]$ is obtained by averaging over the inlet (1) and outlet (2) channels by mass conservation equations for each of them separately:

$$
\begin{gathered}
\frac{d}{d z}\left(\rho \cdot U_{Z, 1}(x)\right)=-\frac{4}{a} \rho \cdot U(x) ; \\
\frac{d}{d z}\left(\rho \cdot U_{Z, 2}(x)\right)=\frac{4}{\alpha} \rho \cdot U(x)
\end{gathered}
$$

The temperature field in the continuum was derived by application of the two-dimensional finite differences scheme (alternate directions method) for the energy conservation equation:

$$
\begin{aligned}
& \rho_{\text {eff }} C_{\text {eff }}\left(\frac{\partial T(x, z)}{\partial t}+v_{z} \times \frac{\partial T(x, z)}{\partial z}\right) \\
& =\lambda_{e f f} \Delta T(x, z)+q_{v o l}(x, z)
\end{aligned}
$$

where: $\rho_{\text {eff }}, C_{\text {eff }}, \lambda_{\text {eff }}$ are effective density, specific heat and conductivity of the filter continuum; $v_{z}$ is a field of longitudinal continuum speeds that are dependent on the radius (as mentioned above, in macro-scale the radial direction flow is equal to zero); $q_{v o l}$ is a volumetric specific power; $t$ - time. $q_{v o l}$ accounts for heat absorption by the channel walls and deposits. It contains the heat flux $q\left[\mathrm{~kW} / \mathrm{m}^{2}\right]$ due to the oxidation reaction of carbon by $\mathrm{O}_{2}$ and $\mathrm{NO}_{2}$ :

$$
\begin{aligned}
& q=\frac{\Delta H_{\mathrm{O}_{2}}}{M_{\mathrm{C}}}\left(\frac{M_{\mathrm{C}}}{M_{\mathrm{O}_{2}}} \cdot \frac{1}{1-f_{\mathrm{CO}} / 2} R_{\mathrm{O}_{2}}\right) \\
& +\frac{\Delta H_{\mathrm{NO}_{2}}}{M_{\mathrm{C}}}\left(\frac{M_{\mathrm{C}}}{M_{\mathrm{NO}_{2}}} \cdot \frac{1}{2-g_{\mathrm{CO}}} R_{\mathrm{NO}_{2}}\right)
\end{aligned}
$$

where $\triangle H_{O 2}, \Delta H_{\mathrm{NO}_{2}}$ are the reaction heats of the corresponding oxidation processes.

In the case of catalytic $\mathrm{O}_{2}-$ oxidation, the value of reaction heat $\Delta H^{c a t}{ }_{O 2}$ must be substituted in eq. (22) instead of $\Delta H_{O 2}$.

\section{Model validation}

The suggested new modification of the classic Bissett equation was validated by comparison of the predicted data on soot oxidation rate by $\mathrm{NO}_{2}$ with those received by Ahmadinejad et al.[14] under isothermal conditions. The results of this comparison are shown in Table 1.

Table 1. Effect of $\mathrm{NO}_{2}$ Inlet Concentration on the Rate of Soot Oxidation

\begin{tabular}{|c|c|c|}
\hline $\begin{array}{c}\text { Change in } \mathrm{NO}_{2} \\
\text { feed }\end{array}$ & $+50 \%$ & $-50 \%$ \\
\hline Data of[25] & $+20 \%$ & $-20 \%$ \\
\hline $\begin{array}{c}\text { Model } \\
\text { prediction }\end{array}$ & $+22 \%$ & $-22 \%$ \\
\hline
\end{tabular}

As can be seen from Table 1, an improvement in the rate of soot oxidation by about $20 \%$ is predicted when the $\mathrm{NO}_{2}$ inlet concentration increases by $50 \%$. Equally, when the $\mathrm{NO}_{2}$ feed decreases by $50 \%$, the rate of soot oxidation is expected to decrease by about $20 \%$. The adopted exponent value of $\zeta=$ 0.5 (eq. 9) provided a good agreement of the predicted and previously published data on soot oxidation rate by $\mathrm{NO}_{2}$.

The model's projection of the pressure drop across DPF was validated by the comparison of predicted data with those experimentally obtained by Mulone et al.[28] at the laboratory engine test bench for testing an 11 liter, 6-cylinder, inline heavy-duty diesel engine, equipped with a state of the art Johnson Matthey CCRT at steady-state conditions. This CCRT consisted of the DOC located upstream a catalyzed DPF. The main geometrical parameters of this aftertreatment system are shown in Table 2[28].

Table 2. Main Geometrical Parameters of the CCRT Used for the Model Validation[28]

\begin{tabular}{|c|c|c|}
\hline \multirow{2}{*}{ Parameter } & \multicolumn{2}{|c|}{ CCRT part } \\
\cline { 2 - 3 } & DOC & CDPF \\
\hline Diameter [cm] & 30.5 & 30.5 \\
\hline Length [cm] & 13 & 30.5 \\
\hline $\begin{array}{c}\text { Cell density } \\
{\left[\text { cell/ } / \mathrm{cm}^{2}\right]}\end{array}$ & 62 & 15.5 \\
\hline $\begin{array}{c}\text { Wall thickness } \\
{[\mathrm{mm}]}\end{array}$ & 4 & 12 \\
\hline
\end{tabular}

A comparison of the predicted data with those measured in[28] was carried out for the two steady-state regimes of CCRT operation: the soot loading (R10) and the regeneration mode (R100). R10 and R100 regimes corresponded to the 10 and $100 \%$ loads, respectively at the engine rating speed. Some relevant parameters of the experiment[28] that were used for the pressure drop predictions are shown in Table 3.

Table 3. Relevant Parameters of the Experiment Applied in the Pressure Drop Predictions

\begin{tabular}{|c|c|c|}
\hline Parameter & R10 mode & R100 mode \\
\hline Fuel consumption $[\mathrm{kg} / \mathrm{h}]$ & 11.6 & 56.1 \\
\hline Intake air flow $\left[\mathrm{sm}^{3} / \mathrm{h}\right]$ & 436 & 999 \\
\hline CCRT inlet temperature $\left[{ }^{\circ} \mathrm{C}\right]$ & 227 & 484 \\
\hline CCRT inlet NO [ppm] & 124 & 361 \\
\hline CCRT inlet $\mathrm{NO}_{2}[\mathrm{ppm}]$ & 40 & 117 \\
\hline CCRT inlet PM $\left[\mathrm{mg} / \mathrm{sm}^{3}\right]$ & 2 & 13 \\
\hline $\begin{array}{c}\text { Soot packing density in the } \\
\text { cake }\left[\mathrm{kg} / \mathrm{m}^{3}\right]\end{array}$ & 40 & 40 \\
\hline
\end{tabular}

A comparison of the measured and predicted pressure drop values for both soot loading and regeneration modes is presented in Fig.1. The obtained results show acceptable agreement between the calculated and experimental data. As can be seen, the model slightly underestimates pressure drop $\Delta p$ across CCRT. Maximal difference between the calculated and measured values of $\Delta p$ does not exceed $10 \%$.

It is known that the overall pressure drop across a DPF is rather complicated and depends on losses through a porous wall and soot cake layer, losses to friction in the channel walls, inertial losses due to expansion/contraction and the Forchheimer effect[38]. Particles withdifferent characteristics have various depths of penetration and packing densities, thus causing large variations in pressure 
drop due to wall loading and soot cake formation. Therefore, accurate prediction of the pressure drop across a DPF in real-world usage conditions is a very challengeable task. It requires very detailed information on engine operation parameters and exhaust emissions, which is hard to be achieved in vehicle fleet tests. Taking this into account, an attempt was made to roughly assess a pressure drop on a CRT over a long period in real-world usage conditions. Typical average values of engine parameters and exhaust emissions were used for this purpose.

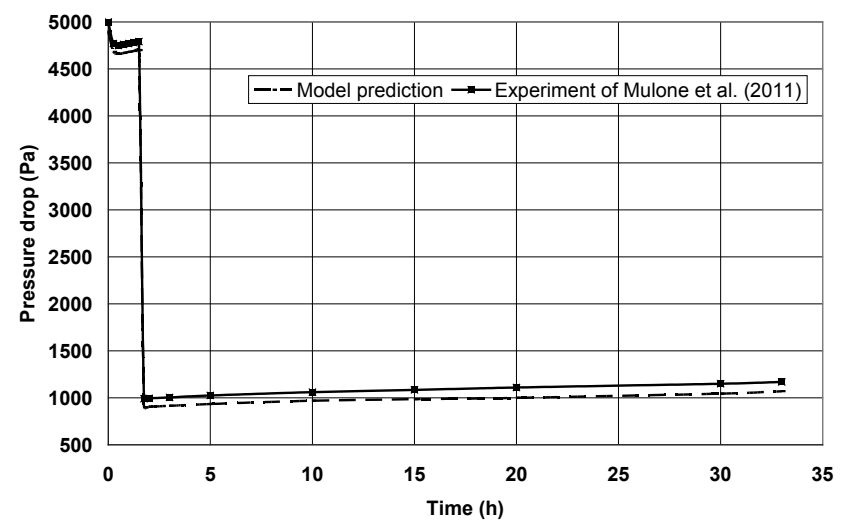

Figure 1. Comparison of the model prediction with the experimental data of Mulone et al.[28] for the pressure drop across CCRT

A comparison was performed with the road test results of two CRTs installed on Mercedes Benz O-405 urban buses equipped by Euro-2 diesel engines (same model), Tartakovsky et al.[39]. During these tests the buses operated at their normal service with the real-world driving pattern typical for bus urban driving. The experiments performed in this study have proved the possibility of CRT successful operation in urban bus during about $2-2.5$ years before the maintenance of ash clean-up. During the first 14 months of CRT operation on the bus, periodical measurements of pressure drop along the CRT were performed. These data have been compared with the results of the model prediction. The CRT that was studied here has the following filter parameters: channel width $2[\mathrm{~mm}]$, its length $305[\mathrm{~mm}]$, diameter $267[\mathrm{~mm}]$, wall thickness $0.43[\mathrm{~mm}]$. It included the DOC and the downstream non-catalyzed DPF. The average value of the measured exhaust gas temperatures was $250^{\circ} \mathrm{C}$. Mass of the ash that comes from the lubricant oil and is accumulated in the DPF was taken into account. The mean values of the DOC inlet $\mathrm{NO}, \mathrm{NO}_{2}$ and $\mathrm{PM}$ emissions were $662[\mathrm{~g} / \mathrm{h}], 203[\mathrm{~g} / \mathrm{h}]$, and $220\left[\mathrm{mg} / \mathrm{sm}^{3}\right]$, respectively. In this work all the mass of PM was assumed to be only elementary or organic carbon.

Estimated values of the pressure drop across the CRT installed and operated in the urban bus, as described above, are shown in Fig. 2 and compared with the measured data obtained in the road tests[39].

The data shown in Fig. 2 demonstrate quite good agreement of the measured and predicted results. The maximal deviation between them does not exceed $20 \%$, which is acceptable for this kind of comparison.
It can be concluded, based on the results of these comparisons, that the developed model can be used for assessment of the DPF suitability to the given vehicle type and its driving conditions.

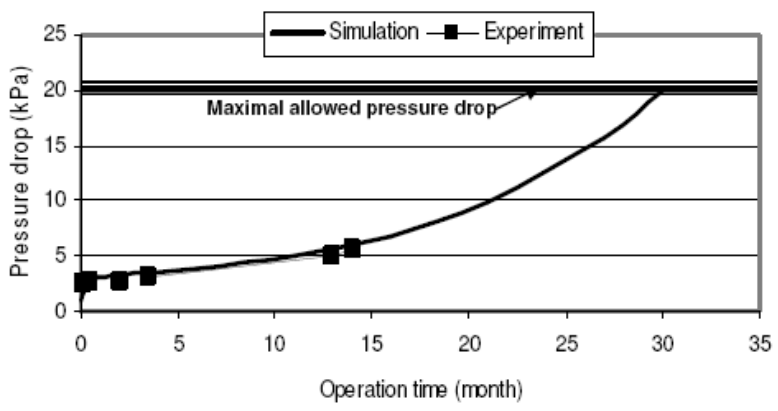

Figure 2. Pressure drop on CRT - comparison of experimental and simulation data

\section{Results and Discussion}

Table 4. Main parameters used in the computations

\begin{tabular}{|c|c|c|}
\hline Parameter & Units & Value \\
\hline Gas flow rate & $\mathrm{sm}^{3} / \mathrm{sec}$ & 0.188 \\
\hline $\begin{array}{c}\text { Soot mass } \\
\text { flow }\end{array}$ & $\mathrm{mg} / \mathrm{sec}$ & 4.2 \\
\hline $\begin{array}{c}\text { Soot Packing } \\
\text { Density in the } \\
\text { Cake }\end{array}$ & $\mathrm{kg} / \mathrm{m}^{3}$ & 40 \\
\hline $\begin{array}{c}\text { Filtering } \\
\text { effectiveness } \\
\text { of DPF }\end{array}$ & - & 0.99 \\
\hline $\begin{array}{c}\text { Oxygen } \\
\text { molar fraction } \\
\text { in the exhaust } \\
\text { gas }\end{array}$ & $\%$ & 12 \\
\hline $\begin{array}{c}\text { Filter channel } \\
\text { width }\end{array}$ & $\mathrm{mm}$ & 305 \\
\hline $\begin{array}{c}\text { Filter channel } \\
\text { length }\end{array}$ & $\mathrm{mm}$ & 229 \\
\hline $\begin{array}{c}\text { Wall } \\
\text { thickness }\end{array}$ & $\mathrm{mm}$ & 0.31 \\
\hline $\begin{array}{c}\text { Filter } \\
\text { diameter }\end{array}$ & $\mathrm{mm}$ & 229 \\
\hline $\begin{array}{c}\text { Channel wall } \\
\text { permeability }\end{array}$ & $\mathrm{m} 2$ & 1.5 \\
\hline
\end{tabular}

The goal of the simulation model described in Section 2 and most of obtained results are the same as in[24]. Nevertheless, wepresume that the proposed model is useful due to its simplicityand new effect observed because of theusingthe two-dimensional scheme for heat transfer calculation. The model was applied for study of the regeneration processes and performance of several DPFs. The results are presented below, for both catalytic and non-catalytic carbon oxidation. The process of oxidation by oxygen is taken into account also in the cases where the leading oxidation mechanism is by $\mathrm{NO}_{2}$. In all the cases of DPF regeneration discussed here the parameters were considered as independent of time. The deposit of ash was 
not taken into account. Main parameters of the DPF geometry and inlet flow that were used in the calculations described below are taken from[27],[40] and listed in Table 4.

Soot thickness parameter was chosen to allow study of the two-dimensional soot accumulation inside a DPF - see Fig. 3-8. This parameter is used for the similar purposes by Mulone et al.[28]. Sometimes the soot cake thickness is calculated to obtain an overall filter permeability, Rakovecet al.[38]. The developed model allows also prediction of the pressure drop across a DPF - Fig. 1, 2. The latter parameter is widely accepted in industry to assess DPF behavior at various usage conditions[1],[41],[42].

\subsection{Catalytic and Non-Catalytic $\mathrm{O}_{2}$-Oxidation}

Fig. 3 shows the soot layer thickness $d$ in the filter channels as a function of the temperature at equilibrium conditions for non-catalytic $\mathrm{O}_{2}$-oxidation and for two values of the activation energy. As can be seen, the levels of $d$ under these conditions are reasonable and lead to pressure drop values on the DPF of less than $0.1 \mathrm{bar}$ at temperatures of $400{ }^{\circ} \mathrm{C}$ and $540^{\circ} \mathrm{C}$ for $E_{a c t}$ of 150 and $180 \mathrm{~kJ} / \mathrm{mol}$, respectively. The latter value, suggested by Bissett[30], seems to be closer to the actual one: according to[12], non-catalytic $\mathrm{O}_{2}$-oxidation requires temperatures of about $600^{\circ} \mathrm{C}$.

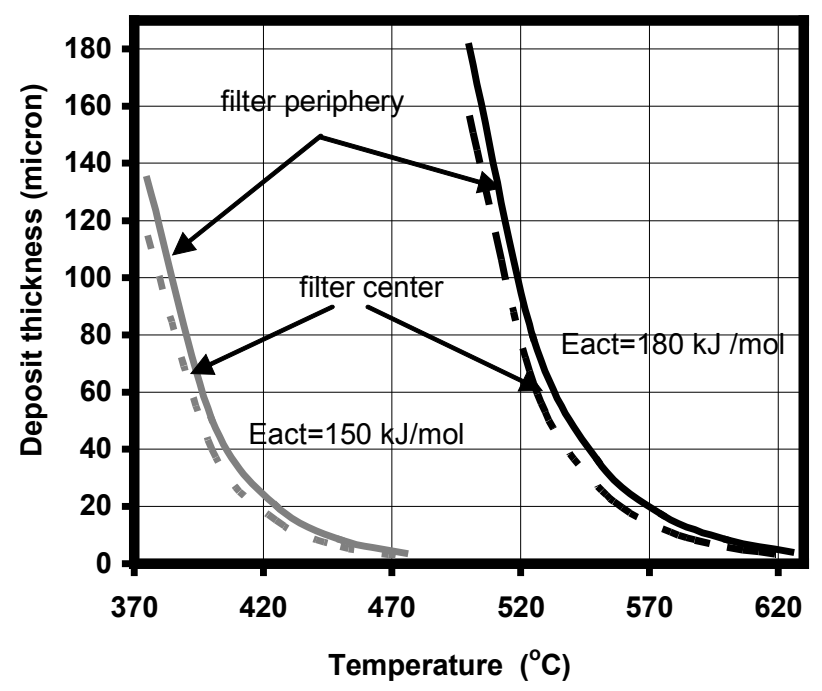

Figure 3. Soot layer thicknesses in the filter channels (in center and periphery) as a function of the temperature: non-catalytic $\mathrm{O}_{2}$-oxidation. Soot mass flow rate $-4.2 \mathrm{mg} / \mathrm{sec}$

\subsection{Critical Temperatures Wherein Clogging of the Filter Periphery Starts}

The curves in Figs. 3 and 4 illustrate thickness of the accumulated soot layer $d$ for the filter center and filter periphery. The slight difference between them results only from heat losses in the filter periphery. The graphs for $d$ as a function of the filter radius are nearly straight lines. For catalytic $\mathrm{O}_{2}$-oxidation (with catalytic coating) the behavior can be much different. Here the soot layer thickness, which is a function of the radial coordinate $x$, and the resulting pressure drop are rather small, until the inlet gas temperature leads to the temperature at the filter periphery (which is lower than the temperature at the filter center due to heat losses on the outer filter surface) that is higher than a fixed critical value, $T_{c r}$. At temperatures lower $T_{c r}$ a clogging process will start from the filter periphery and continue to full clogging of the filter. The latter effect is a consequence of the filter conductivity increase in the clogged zone. When the soot layer thickness becomes higher than $d_{l}$, the catalytic fraction $\beta$ in the second layer becomes equal to zero, and the catalytic oxidation process is interrupted there. This normally leads to accelerated soot accumulation. If the filter wall temperature at the periphery is lower than $T_{c r}$ and the temperature at the filter center is still above $T_{c r}$, the soot accumulation at the filter periphery channels may drastically exceed that in the filter center. The calculations, using the constant $\beta$ approach, show that for $\beta=0.5$ (this value is taken according to[15]), $d_{l}=10 \mu \mathrm{m}$, (as in[19]) and $E_{a c t}=$ $140 \mathrm{~kJ} / \mathrm{mol}$ (according to the review[37]) catalytic coating reduces $E_{a c t}$ by $30-80 \mathrm{~kJ} / \mathrm{mol}$ and $T_{c r}=470^{\circ} \mathrm{C}$. In the case of using the variable $\beta$ approach according to eq. (14), the same $E_{a c t}$ and the same value of $\beta(0)=0.5$, give $T_{c r}=511^{\circ} \mathrm{C}$. The former value is too 'optimistic': many published experimental results indicate that catalytic coating can reduce oxidation temperatures by $13-42^{\circ} \mathrm{C}$ only, e.g.[22]. Indeed, for the non-catalytic $\mathrm{O}_{2}$-oxidation, as was mentioned earlier, the predicted value of acceptable temperaturewas $540{ }^{\circ} \mathrm{C}$. The case of a more active catalytic coating with activation energy reduced down to $120 \mathrm{~kJ} / \mathrm{mol}$ (reduction of $60 \mathrm{~kJ} / \mathrm{mol}$ compared to the value of $180 \mathrm{~kJ} / \mathrm{mol}$ that is relevant for the non-catalytic $\mathrm{O}_{2}$ oxidation) was studied too. For this case (the other parameters were kept as before) the value of $T_{c r}=400^{\circ} \mathrm{C}$ was obtained. The most optimistic scenario of $E_{\text {act }}$ reduction to $100 \mathrm{~kJ} / \mathrm{mol}$ gives $T_{c r}$ value of $303^{\circ} \mathrm{C}$.

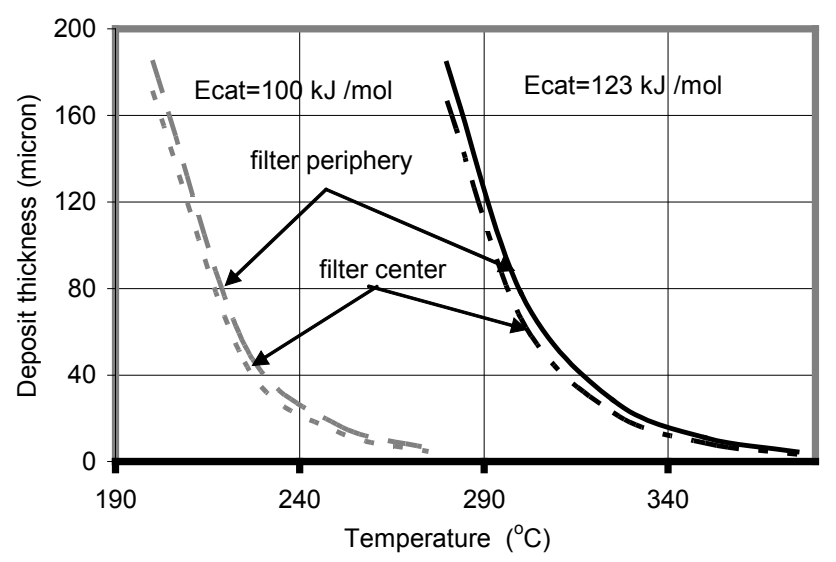

Figure 4. Soot layer thickness in the filter channels (in center and periphery) as a function of the temperature: $\mathrm{O}_{2}$ - oxidation with a fuel-borne catalyst $(\beta=0.95)$. Soot mass flow rate $-4.2 \mathrm{mg} / \mathrm{sec}$

Calculations of the filter clogging process near the critical temperature of $335^{\circ} \mathrm{C}$ are presented in Fig. 5 for the activation energy of $120 \mathrm{~kJ} / \mathrm{mol}$ (relevant for the catalytic soot oxidation). It should be noted here that in the real engine 
operation an increase in the backpressure will inevitably lead to the raise of engine-out (DPF inlet) exhaust gas temperature. As a result, the process of soot accumulation in the vicinity of critical temperature will be appropriately slowed down. This phenomenon is not taken into account in the modeling and not reflected in Fig.5.

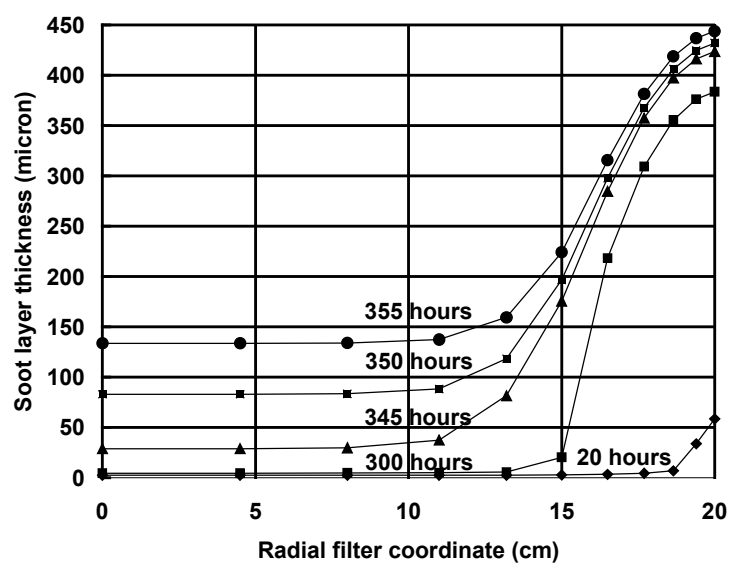

Figure 5. Filter clogging dependenceon time. Soot mass flow rate -4.2 $\mathrm{mg} / \mathrm{sec}$

\section{3. $\mathrm{FBC}$ - and $\mathrm{NO}_{2}$ - Oxidation}

Fig. 4 shows the soot layer thicknesses for carbon oxidation by means of FBC for two values of the activation energy: $100[40]$ and $123 \mathrm{~kJ} / \mathrm{kmol}$. The latter has been obtained by Fino\&Specchia[17] using perovskite on $\mathrm{CeO}_{2}$ catalyst. The results in Fig. 4 for the soot layer thickness $d$ are obtained for $\beta=0.95$. This value of catalytic fraction is chosen, as a conservative reproduction of the value $\beta=0.97$ suggested by Konstandopoulos\&Kostoglou[15]. As can be seen from Fig.4, acceptable temperatures for filter operation start at $220^{\circ} \mathrm{C}$ and $310^{\circ} \mathrm{C}$, respectively. These temperatures are sufficiently low even for the latter case of $E_{a c t}$. The comparison of these results with the latest experimental data of Rocher et al.[10] on development of the Fe-based FBC shows that activation energy value of $100 \mathrm{~kJ} / \mathrm{kmol}$ is too optimistic. The value of $123 \mathrm{~kJ} / \mathrm{kmol}$ gives much more realistic results for the temperatures of soot burning with aid of nowadays available FBC.

The modelling results for non-catalytic $\mathrm{NO}_{2}$-oxidation process together with $\mathrm{O}_{2}$-oxidation are displayed in Fig. 6 for the two values of nitrogen oxide concentration: 100 and 200 ppm.

In this case, following eq. (12) the soot layer thickness dependence on temperature is non-monotonic. In these calculations the values of $E^{(l)}{ }_{N O 2}=45.5 \mathrm{~kJ} / \mathrm{mol}$ for $\mathrm{C}+2 \mathrm{NO}_{2} \rightarrow \mathrm{CO}_{2}+2 \mathrm{NO}$ and $E^{(2)}{ }_{\mathrm{NO} 2}=59.4 \mathrm{~kJ} / \mathrm{mol}$ for the $\mathrm{C}+\mathrm{NO}_{2} \rightarrow \mathrm{CO}+\mathrm{NO}$ reaction[17] have been used. The corresponding soot depositions are acceptable (pressure drop values of less than 0.1 bar) at temperatures higher than $270^{\circ} \mathrm{C}$ and $325^{\circ} \mathrm{C}$ for $\mathrm{NO}$ concentrations of 200 and $100 \mathrm{ppm}$, respectively. The former value of $T$ is very promising, whereas the latter is less acceptable, because lower temperatures prevail quite often in real driving patterns. Moreover, prediction results show that relatively low NO concentration (100ppm) yields too large soot layer thicknesses also in the medium $T$-range $450-510^{\circ} \mathrm{C}$. In this range, the $\mathrm{NO}_{2}$-oxidation process is damped out, because of reduced $\mathrm{NO}$ to $\mathrm{NO}_{2}$ conversion (according to eq. (12)), while the $\mathrm{O}_{2}$-oxidation does not occur yet. At higher $T$, the two curves in Fig. 6 coincide, since the $\mathrm{O}_{2}$-oxidation process dominates. It is possible to completely avoid the disadvantage of increasing the soot layer thickness at medium temperatures of $450-510{ }^{\circ} \mathrm{C}$ by means of a combination of $\mathrm{NO}_{2}$ - and $\mathrm{O}_{2}$ - oxidation processes using a catalyst coating.

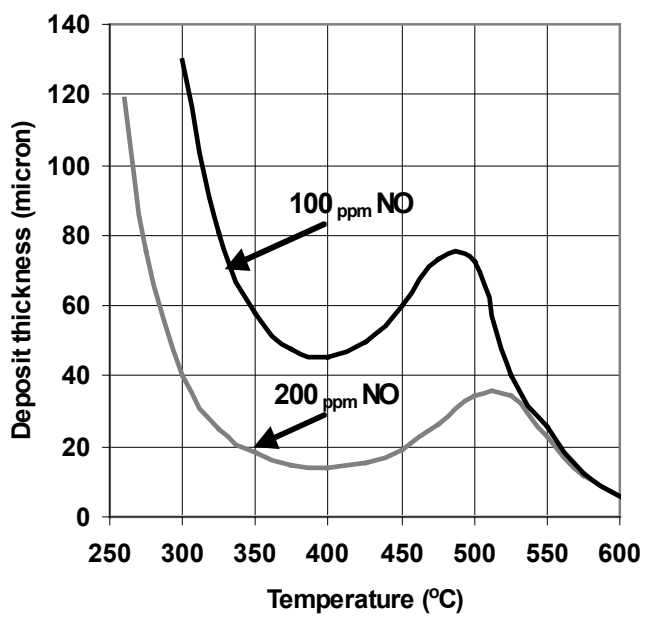

Figure 6. Soot layer thickness in the filter channels as a function of the temperature: $\mathrm{O}_{2}$ - and $\mathrm{NO}_{2}$-oxidation without catalyst. Soot mass flow rate$4.2 \mathrm{mg} / \mathrm{sec}$

Fig. 7a presents results for the catalytic coating, $\beta(0)=0.5$, $d_{l}=10 \mu \mathrm{m}$ and $E_{a c t}=140 \mathrm{~kJ} / \mathrm{mol}$. An abrupt fall of both curves is observed when the temperature approaches the $T_{c r}=$ $511{ }^{\circ} \mathrm{C}$ value of the catalytic $\mathrm{O}_{2}$ oxidation (the lower $\mathrm{NO}$ concentration the closer $T$ fall to $T_{c r}$ ). At higher temperatures, the two curves in Fig. 7a merge, as also observed is Fig. 6, since the catalytic $\mathrm{O}_{2}$-oxidation dominates in this range. As can be seen from the comparison of data shown in Fig. 6 and $7 \mathrm{a}$, the use of the catalytic coating that enables reduction of $E_{\text {act }}$ down to $140 \mathrm{~kJ} / \mathrm{mol}$ does not lead to any substantial improvement of soot oxidation at medium temperatures. Therefore, the possible impact of a more effective catalyst is studied. For example, the catalyst that enables reduction of the activation energy value down to $123 \mathrm{~kJ} / \mathrm{mol}$ was considered. The predicted results of catalytic $\mathrm{O}_{2}$-and $\mathrm{NO}_{2}$-oxidation for the same values of $\beta(0)=0.5, d_{l}=$ $10 \mu \mathrm{m}$ and $E_{a c t}=123 \mathrm{~kJ} / \mathrm{mol}$ are shown in Fig. $7 \mathrm{~b}$.

As can be seen from Fig. $7 b$, this allows significant reduction of the soot layer thickness at medium temperatures and, therefore substantial improvement of the DPF regeneration performance.The results presented in Fig. 6, $7 \mathrm{a}, \mathrm{b}$ are in a good agreement with those obtained by Soeger et al.[43] that at temperatures higher than $380^{\circ} \mathrm{C}$ there is an inflection point in the curve indicating a sharp increase in soot burning rate (in this work - sharp reduction of soot 
deposit thickness - Fig.7b). This behavior is explained by an increased contribution of oxygen-based soot combustion prevailing soot-by- $\mathrm{NO}_{2}$ oxidation and compensates for the decreased $\mathrm{NO}_{2}$ formation at temperatures higher than $300^{\circ} \mathrm{C}$.

In addition to the discussed above study of catalytic $\mathrm{O}_{2}$-and $\mathrm{NO}_{2}$-oxidation, a similar process is investigated, where instead of catalytic coating a fuel-borne catalyst is used. Results obtained for the FBC case are presented in Fig. 8 , for the same two concentrations of nitrogen oxide $(100$ and 200ppm), as well as the same catalytic fraction values of $\beta=0.95$ and activation energy $E_{\text {act }}=120 \mathrm{~kJ} / \mathrm{mol}$, that were used in the study of $\mathrm{O}_{2}$-oxidation with FBC (see Fig. 4).

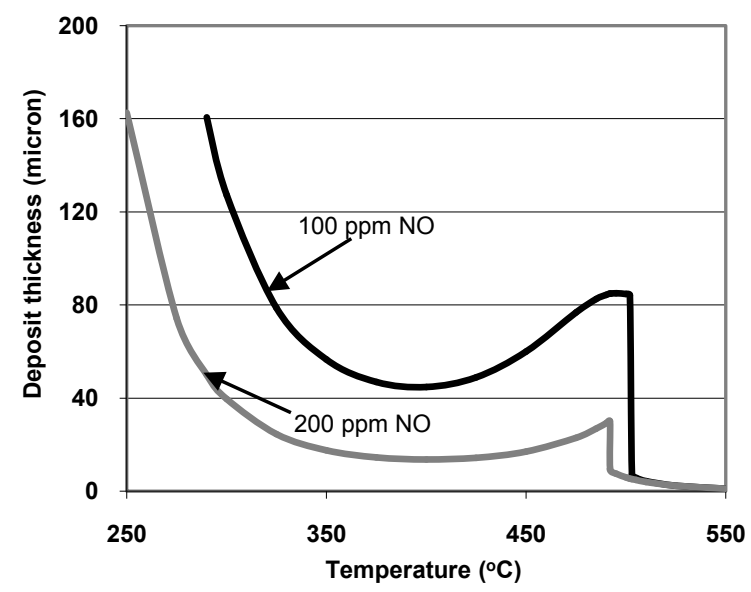

Figure 7. Soot layer thicknesses in the filter channels as a function of the temperature: $\mathrm{O}_{2}$ - and $\mathrm{NO}_{2}$-oxidation with catalytic coating. a) $E_{\text {act }}=140$ $\mathrm{kJ} / \mathrm{mol}$; b) $E_{\text {act }}=123 \mathrm{~kJ} / \mathrm{mol}$. Soot mass flow rate $-4.2 \mathrm{mg} / \mathrm{sec}$

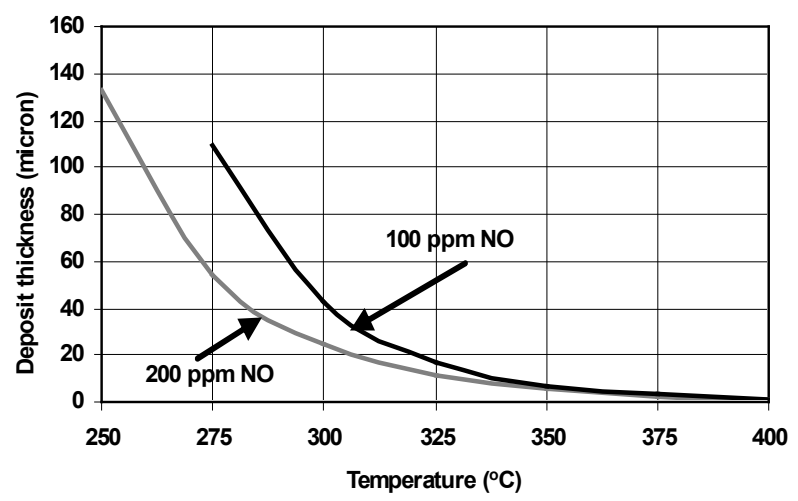

Figure 8. Soot layer thicknesses in the filter channels as a function of the temperature: $\mathrm{O}_{2}$ - and $\mathrm{NO}_{2}$-oxidation with $\mathrm{FBC}$. Soot mass flow rate -4.2 $\mathrm{mg} / \mathrm{sec}$

In the case presented in Fig. $8\left(\mathrm{O}_{2}\right.$-and $\mathrm{NO}_{2}$-oxidation catalytic process with $\mathrm{FBC}$ ), the minimal temperatures corresponding to acceptable pressure drop on the DPF are lower than those achieved with a non-catalytic or catalytic (coating) $\mathrm{O}_{2}$-and $\mathrm{NO}_{2}$-oxidation (see Figs. 6 and $7 \mathrm{~b}$, respectively), as well as with the $\mathrm{O}_{2}$-oxidation by $\mathrm{FBC}$ for the same value of the activation energy $E_{a c t}=120 \mathrm{~kJ} / \mathrm{mol}$ (Fig. 4). The reason for this is the fact that in the case of $\mathrm{FBC}$, the catalytic $\mathrm{O}_{2}$-oxidation process starts at lower temperatures (compared to the catalytic coating) at the same activation energy of the reaction, since the fuel-borne catalyst affects the reaction in the whole soot layer. Therefore, in this case the acceptable minimal exhaust gas temperatures are $265^{\circ} \mathrm{C}$ and $285^{\circ} \mathrm{C}$ for $\mathrm{NO}$ concentrations of 200 and $100 \mathrm{ppm}$, respectively. The same results were obtained by Shejbal et al. [24]. In the latter, soot was significantly oxidized by $\mathrm{O}_{2}$ and $\mathrm{NO}_{2}$ at temperatures above $250^{\circ} \mathrm{C}$. The disadvantages of $\mathrm{FBC}$ using were discussed above.

\section{Conclusions}

The developed model, based on the proposed new approach and corresponding computer code, enables comparative study of various DPFregeneration methods.

New expression for the reaction rate of soot oxidation with non-linear dependence of it on a reagent concentration is proposed.It makes possible simulation of both $\mathrm{O}_{2-}$ and $\mathrm{NO}_{2}$-carbon oxidation reactions. For cases of catalytic coating a modification of the known two-layer model is suggested. According to this modified model, a fraction of soot that is oxidized with the help of catalytic coating is not invariable in the first layer, but it exponentially depends on the distance from a channel wall of the particle trap. Heat transfer in the particle trap as a continuum is considered by the two dimensional finite differences scheme.

Soot oxidation in diesel particulate filters by $\mathrm{O}_{2}$, as well as $\mathrm{NO}_{2}$ with $\mathrm{O}_{2}$, have been investigated for various cases of non-catalytic oxidation and oxidation in presence of catalytic coating and fuel-borne catalyst. In the case of soot oxidation using catalytic coating, the phenomenon of critical temperature emergence was observed at first. It can be explained in the framework of the applied two-layer model by abrupt reduction of the reaction rate at the border of the second layer. Calculation results of soot oxidation by $\mathrm{NO}_{2}$ with $\mathrm{O}_{2}$ using catalytic coating show that soot is significantly oxidized at temperatures above $250^{\circ} \mathrm{C}$. This finding is in a good agreement with data obtained by Shejbal et al. [24].

Dependence of the soot oxidation in presence of catalytic coating on activation energy is quite weak at relatively low temperatures of $250-350^{\circ} \mathrm{C}$ and strongly enhances with the temperature rise. This can be clearly illustrated for the case of NO concentration equal $200 \mathrm{ppm}$ by the fact that the soot layer thickness of 160 micron is achieved almost at the same temperature of $250^{\circ} \mathrm{C}$ for both studied values of $E_{\text {act }}(140$ and $123 \mathrm{~kJ} / \mathrm{mol}$ ). Conversely, at higher temperatures almost full soot burnout is achieved at $390^{\circ} \mathrm{C}$ for $E_{\text {act }}=123 \mathrm{~kJ} / \mathrm{mol}$ compared with $500^{\circ} \mathrm{C}$ for $E_{a c t}=140 \mathrm{~kJ} / \mathrm{mol}$.

The developed model allows selection of an acceptable soot oxidation method depending on available exhaust gas temperatures and nitrogen oxides concentrations. In future research the model can be further developed to cover other methods of soot regeneration that were not addressed in this study. The Bissett - type equations (such as eq. 1) can be a good approximation for modeling more complicated cases with more reactants. 


\section{ACKNOWLEDGEMENTS}

This work was supported by the Israeli Ministry of Environment Protection (grant number 4-107 (2008409)).

\section{REFERENCES}

[1] T. V. Johnson,"Review of diesel emissions and control", SAGE Journals, International Journal of Engine Research, vol.10, no.5,pp.275-285, 2009.

[2] A.G. Konstandopoulos, E. Papaioannou,"Update on the science and technology of diesel particulate filters",Hosokava Powder Technology Foundation, KONA Powder and Particle Journal,vol.26,pp.36-65, 2008.

[3] L. Tartakovsky, S. Hausberger, M. Gutman, M. Veinblat, and Y. Zvirin,"Retrofit aftertreatment systems for diesel engines", in Proceedings of the 14th International Scientific Symposium on Transport and Air Pollution, pp.221-230,2005.

[4] K Sung, J Kim, R D Reitz,"Experimental study of pollutant emission reduction for near-stoichiometric diesel combustion in a three-way catalyst",SAGE Journals, International Journal of Engine Research, vol.10, no.5,pp.349-357, 2009.

[5] J. Warner, D. Dobson, G. Cavataio,"A Study of Active and Passive Regeneration Using Laboratory Generated Soot on a Variety of SiC Diesel Particulate Filter Formulations", SAE International Journal on Fuels \&Lubricants, vol.3, no.1, pp.149-164, SAE Paper 2010-01-0533,2010.

[6] H Kato, K Ito, H Suda, J Kusaka, T Mori, F Tsurumi, N Masaki, K Hirata, $\mathrm{H}$ Akagawa, "Development of a Quasi-Two-Dimensional Model for Analyzing Continuous Regeneration-Diesel Particulate Filter States during Continuous and Active Regeneration", SAGE Journals, International Journal of Engine Research, vol.12,no.1,pp.1-13,2011.

[7] P. Roth, T. Eckhardt, B. Franz, J. Patschull," $\mathrm{H}_{2} \mathrm{O}_{2}$-assisted regeneration of diesel particulate traps at typical exhaust gas temperatures", Elsevier, Combustion \& Flame,vol.115, p.28,1998.

[8] H. Christensen, J. Dinesen, H. Engell, K. Hansen,"Electrochemical reactor for exhaust gas purification", SAE Technical Paper, 1999-01-0472, 1999.

[9] B. W. L. Southward, S. Basso, M. Pfeifer,"On the development of low PGM content direct soot combustion catalysts for diesel particulate filters", SAE Technical Paper, 2010-01-0558, 2010.

[10] L. Rocher, T. Seguelong, V. Harle, M. Lallemand, M. Pudlarz, M. Macduff,"New generation fuel borne catalyst for reliable DPF operation in globally diverse fuels", SAE Technical Paper, 2011-01-0297, 2011.

[11] P. Hawker, N. Myers, G.Huthwohl, H. Vogel, B.Bates, L. Magnusson, P. Bronneberg,"Experience with a new particulate trap technology in Europe", SAE Technical Paper, $970182,1997$.

[12] A. Messerer, R. Niessner, U. Posch,"Comprehensive kinetic characterization of the oxidation and gasification of model and real diesel soot by nitrogen oxides and oxygen under engine exhaust conditions: measurement, Langmuir-Hinshel wood and Arrhenius parameters",Elsevier, Carbon,vol.44,pp.307-324, 2006.

[13] A.G. Konstandopoulos, M. Kostoglou, E. Scaperdas, E. Papaioannou, D. Zarvalis, E. Kladopoulou,"Fundamental Studies of DPF", SAE Technical Paper, 2000-01-1016, pp. 683-705,2000.

[14] M. Ahmadinejad, A. Tsolakis, J.M. Becker, C.F. Goersmann, A.D. Newman, T.C. Watling,"Modeling of soot oxidation by NO2 in a Diesel Particulate Filter", SAE 2011-01-2083, pp. 115-125, 2011.

[15] A.G. Konstandopoulos, M. Kostoglou,"Reciprocating flow regeneration of soot filters", Elsevier, Combustion and Flame, vol.121, pp.488-500, 2000.

[16] F. Jacquot, V. Logie, J.F. Brilhac, P. Gilot,"Kinetics of the oxidation of carbon black by $\mathrm{NO}_{2}$ - influence of the presence of water and oxygen", Elsevier, Carbon,vol.40,pp.335-343, 2002.

[17] D. Fino, V. Specchia,"Compositional and structural optimal design of a nano-structured diesel-soot combustion catalyst for a fast-regenerating trap",Elsevier, Chemical Engineering Science,vol.59,pp.4825-4836, 2004.

[18] P. Palmisano, N. Russo, P. Fino, D. Fino, C. Badini,"High catalytic activity of SCS-synthesized cerium towards diesel soot combustion",Elsevier, Applied Catalysis B: Environmental,vol.69,pp.85-92, 2006.

[19] A.G. Konstandopoulos, M. Kostoglou,"Periodically reversed flow regeneration of diesel particulate traps", SAE Technical Paper, 1999-01-0468,pp.289-302,1999.

[20] A.G. Konstandopoulos, E. Skaperdas, J. Warren, R. Allansson,"Optimized filter design and selection criteria for continuously regenerated particle traps", SAE Technical Paper, 1999-01-0468,pp.279-288,1999.

[21] S. Jelles, M. Makkee, J. Moulijn, J. Acres, J. Peter-Hoblyn,"Diesel particulate control", SAE Technical Paper, 1999-01-0113,pp.69-74,1999.

[22] K. Hinot, H. Burtscher, A.P. Weber, G. Kasper,"The effect of the contact between platinum and soot particles on the catalytic oxidation of soot deposits on a diesel particle filter",Elsevier, Applied Catalysis B: Environmental, vol.71,pp.271-278,2007.

[23] M. Gutman, L. Tartakovsky, Y. Zvirin,"Pollutant Formation and Control: Fuel Effects on Emissions", In: E. Sher (ed) Handbook of Air Pollution From Internal Combustion Engines. Academic Press, pp. 548 - 651, 1998.

[24] M. Schejbal, M. Marek, M. Kubicek, P. Koci,"Modeling of diesel filters for particulates removal", Elsevier, Chemical Engineering Journal,vol.154,pp.219-230, 2010.

[25] J.S. Howitt, M.R. Montierth,"Cellular ceramic diesel particulate filter", SAE Technical Paper, 810114,pp.493-501,1981.

[26] R. Aris, "De exemblosimulacrorumcontinuorum discrita-lu mque",Springer, Archive for Rational Mechanics and Analysis,vol.70, pp.203-212, 1979.

[27] Z. Zhang, S.L. Yang, J.H. Johnson,"Modeling and numerical simulation of diesel particulate trap: performance during 
loading and regeneration", SAE Technical Paper, 2002-01-909,pp.1399-1411,2002.

[28] V. Mulone, A. Cozzolini, P. Abeyratne, D. Littera, M. Thiagarajan, M.C. Besch, M. Gautam,"Soot modeling for advanced control of diesel engine aftertreatment", ASME, Journal of Engineering for Gas Turbines and Power,vol.133, pp.122804-1 - 122804-12,2011.

[29] H. Mohammed, A.P. Triana, S.L. Yang, J.H. Johnson,"An advanced 1D 2-layer catalyzed diesel particulate filter model to simulate: filtration by the wall and particulate cake, oxidation in the wall and particulate cake by $\mathrm{NO}_{2}$ and $\mathrm{O}_{2}$ and regeneration by heat addition", SAE Technical Paper, 2006-01-467, pp.171-191,2006.

[30] E.J. Bissett,"Mathematical model of the thermal regeneration of a wall flow monolith diesel particulate filter",Elsevier, Chemical Engineering Science,vol.39,pp.1233-1244, 1984.

[31] C.T. Huynh, J.H. Johnson, S.L. Yang, S.T. Bagley, J.R. Warner,"A one-dimensional computational model for studying the filtration and regeneration characteristics of a catalyzed wall-flow diesel particulate filter", SAE Technical Paper, 2003-01-0841,pp.620-646, 2003.

[32] M. Jeguirim, V. Tschamber, J.F. Brilhac,"Kinetics of catalyzed and non-catalyzed soot oxidation with nitrogen dioxide under regeneration particle trap conditions",Wiley, Journal of Chemical Technology and Biotechnology,vol.84,p p.770-776,2009.

[33] M. Jeguirim, K. Villani, J.F. Brilhac and J.A. Martens,"Ruthenium and platinum catalyzed carbon oxidation: a comparative kinetic study",Elsevier, Applied Catalysis B: Environmental,vol.96,pp.34-40,2010.

[34] B.J. Cooper, J.E. Thoss,"Role of NO in diesel particulate emission control", SAE Technical Paper, 890404,pp.612-624,1989.

[35] P. Darcy, P. Da Costa, H. Mellottee, J.M. Trichard, G. Djega-Mariadassou,"Kinetic of catalyzed and non-catalyzed oxidation of soot from a diesel engine",Elsevier, Catalysis Today,vol.119, pp.252-256,2007.

[36] A.G. Konstandopoulos, J.H. Johnson,"Wall-flow diesel particulate filters-their pressure drop and collection efficiency", SAE Technical Paper, 890405,pp.625-647,1989.

[37] P. Versaevel, H. Colas, C. Rigaudeau, R. Noirot, G.S. Koltsakis, A.M. Stamatelos,"Some empirical observations on diesel particulate filter modeling and comparison between simulations and experiments", SAE Technical Paper, 2000-01-0477,pp.312-323,2000.

[38] N. Rakovec, S. Viswanathan, D. Foster,"Micro-scale study of DPF permeability as a function of PM loading", SAE Technical Paper, 2011-01-0815,pp.913-921,2011.

[39] L. Tartakovsky, J. Czerwinski, Y. Aleinikov, B. Aronov, V. Baybikov, M. Gutman, M. Veinblat, Y. Zvirin,"Retrofitting of urban buses in Israel with particulate traps - first results", in Proceedings of the 13th World Clean Air and Environmental Protection Congress (IUAPPA), Transport, Environment and the Sustainable City, Paper No. 1, 2004.

[40] B.R. Stanmore, J.F. Brilhac, P. Gilot,"The oxidation of soot: a review of experiments, mechanisms and models", Elsevier, Carbon,vol.39,pp.2247-2268,2001.

[41] ShujiFujii, Tsuyoshi Asako,"Design optimization of non-catalyzed DPF from viewpoint of back pressure in ash loading state", SAE Technical Paper, 2011-01-2091,pp.687-6 98,2011 .

[42] T. V. Johnson,"Review of diesel emissions and control", SAE Technical Paper, 2010-01-0301,pp.16-29,2010.

[43] N. Soeger, L. Mussmann, R. Sesselmann, G. Leippe, C. Gietzelt, O. Bailey, M. Hori,"Impact of aging and $\mathrm{NO}_{\mathrm{x}} /$ Soot ratio on the performance of a catalyzed particulate filter for heavy duty diesel applications", SAE Technical Paper, 2005-01-0663, 14p., 2005. 